\title{
APTES-Functionalization of SBA-15 Using Ethanol or Toluene: Textural Characterization and Sorption Performance of Carbon Dioxide
}

\author{
Laura Munguía-Cortés, ${ }^{1}$ Isaac Pérez-Hermosillo, ${ }^{1}$ Reyna Ojeda-López, ${ }^{1}$ Juan Marcos Esparza-Schulz, ${ }^{1}$ \\ Carlos Felipe-Mendoza, ${ }^{2}$ Adrián Cervantes-Uribe ${ }^{3}$ and Armando Domínguez-Ortiz ${ }^{1, *}$
}

${ }^{1}$ Departamento de Química, Fisicoquímica de Superficies. Universidad Autónoma Metropolitana-Iztapalapa. Av. San Rafael Atlixco 186, Col. Vicentina, Ciudad de México, 09340.

2 Departamento de Biociencias e Ingeniería, CIIEMAD, Instituto Politécnico Nacional. 30 de Junio de 1520 s/n, La Laguna Ticoman, Ciudad de México, 07340.

${ }^{3}$ División Académica de Ciencias Básicas, DACB, Universidad Juárez Autónoma de Tabasco. Carretera Cunduacán-Jalpa de Méndez, Cunduacán, Tabasco, 86690.

* doar@xanum.uam.mx

Received March 1 ${ }^{\text {st }}, 2017$; Accepted June 19 ${ }^{\text {th }}, 2017$

\begin{abstract}
SBA-15 materials were functionalized with amino groups, APTES. The functionalization was carried out with ethanol or toluene, in air or nitrogen atmosphere. Texture and silanol ratio of functionalized materials were characterized by $\mathrm{CO}_{2}$ adsorption, $\mathrm{N}_{2}$ adsorption, SEM, TEM, and NMR. The results of this work indicates that functionalization in toluene is better than functionalization in ethanol, in order to anchor the largest number of APTES molecules on SBA-15 surface. For the same purpose, during functionalization process, the use of nitrogen atmosphere is better than the use of air atmosphere. Key words: APTES, $\mathrm{CO}_{2}$ adsorption, functionalization, SBA-15, silanol ratio.
\end{abstract}

\section{Introduction}

Synthesis and characterization of materials, combining reactivity of organic functional groups with thermal and structural silica advantages, have been extensively studied [1-3], due to functionalized silica has important applications in biochemistry, electrochemistry $[4,5]$, and adsorption [6,7], among others disciplines. For instance, amino functionalized SBA-15 has shown high thermal stability, high chemical resistance, and great capacity to capture $\mathrm{CO}_{2}$ [8-12]. SBA-15 materials are characterized by a large surface area and micropores interconnecting mesoporous channels [13]. Preparation of these materials involves a calcination process to remove residual organic material [14]. The temperature used in this step determines the concentration of silanol groups ( $\mathrm{Si}-\mathrm{OH})$ on the SBA-15 surface $[15,16]$. These groups allow chemical "anchorage" of amine groups $[4,5,7]$. In general, there are two approaches to anchor amine molecules at SBA-15 surface, these are as follows [17]:

i) post-modification or grafting; a covalent bond between amine groups and silanol groups (free and germinal) oc-
Resumen: Materiales mesoporosos SBA-15 se funcionalizaron con APTES. La funcionalización se realizó en etanol o en tolueno, bajo atmósfera de aire o de nitrógeno. La textura y la proporción de grupos silanol de los materiales funcionalizados, se caracterizaron mediante adsorción de $\mathrm{CO}_{2}$, adsorción de $\mathrm{N}_{2}$, SEM, TEM y RMN. Los resultados obtenidos en este trabajo señalan que la funcionalización en tolueno es mejor que la funcionalización en etanol, si se quiere anclar el mayor número de moléculas APTES en la superficie del SBA-15. Con el mismo propósito, durante el proceso de funcionalización, el uso de una atmósfera de nitrógeno es mejor que el uso de una atmósfera de aire.

Palabras clave: APTES, adsorción de $\mathrm{CO}_{2}$, funcionalización, SBA15, proporción de grupos silanol.

curs in this approach $[18,19]$. This is the most used method to perform SBA-15 surface modification, because it favors amine groups anchoring in mesopores [20].

ii) direct synthesis or co-condensation; it allows a single step SBA-15 surface modification, by co-polymerization of amine groups with silica precursors [19].

In this work, grafting method was used to anchor amine molecules on SBA-15 surface. Triethoxysilane (3-aminopropyl), better known as APTES, was used as the functionalizing agent. According to the literature, functionalization of SBA-15 is performed with toluene [21-23], a flammable and toxic solvent. So that, we explore the use of a solvent more friendly to the environment, such as ethanol. Lombardo [24] has studied the effect of solvents, such as ethanol or toluene, on the amine functionalization of silica materials. Nevertheless, this study was not conclusive; particularly since $\mathrm{CO}_{2}$ adsorption capacity of these porous materials was not evaluated. Additionally, this work was evaluated the effect of using a nitrogen atmosphere or an air atmosphere over the efficiency of chemical anchorage, during the process of functionalization. 
This manuscript is organized as follows: First, the synthesis and subsequent functionalization of SBA-15 materials is presented. Then, the characterization techniques used in this work are described. Afterwards, the results are given and discussed. The most suitable conditions for anchoring APTES molecules on SBA-15 surface are identified.

\section{Materials and methods}

\subsection{Materials}

Tetraethylorthosilicate(TEOS, 98\%,Aldrich), surfactantpoly(ethylene glycol)-block-poly(propylene glycol)-block-poly(ethylene glycol) (P-123, Aldrich), (3-aminopropyl)triethoxysilane (APTES, $99 \%$, Aldrich), hydrochloric acid (36.5-38 \%, J.T. Baker), absolute ethanol (EtOH, $99.9 \%$, Baker) and toluene $\left(\mathrm{C}_{6} \mathrm{H}_{5} \mathrm{CH}_{3}\right.$, $99.5 \%$, Merck) were used, without further purification.

\subsection{Synthesis of the materials}

\subsubsection{SBA-15 synthesis}

The preparation of pristine silica SBA-15 samples was akin to the method reported by Zhao et al. [3].

i) About $4.0 \mathrm{~g}$ of triblock copolymer Pluronic P-123 was dissolved in a solution of $120 \mathrm{~g}$ of deionized water and $24 \mathrm{~g}$ of $36.5-38.0 \% \mathrm{HCl}$ under stirring until complete dissolution. Next, it was performed the addition of 8.5 $\mathrm{g}$ of TEOS dropwise. The mixture was stirred at 313 $\mathrm{K}$ for $20 \mathrm{~h}$ and then was aged at $353 \mathrm{~K}$ for two days without mixing.

ii) Sample was recovered by filtration, washed with 150 $\mathrm{mL}$ of ethanol, and air-dried at $373 \mathrm{~K}$ for $24 \mathrm{~h}$. The organic template was removed by calcination in air at $623 \mathrm{~K}$ in a tube furnace; this temperature produces the highest superficial concentration of silanol groups $[15,16]$. During calcination process, temperature rose $1 \mathrm{~K}$ per minute up to $623 \mathrm{~K}$; afterwards temperature was kept constant during $4 \mathrm{~h}$.

\subsubsection{SBA-15 amino-functionalization}

All functionalized systems (amino-functionalized SBA-15 materials) were obtained from a SBA-15 samples calcined at $623 \mathrm{~K}$.

Functionalization of SBA-15 materials with APTES was performed as follows ( $c f$ Fig. 1):

i) About $0.50 \mathrm{~g}$ of SBA-15 was outgassed under vacuum at $373 \mathrm{~K}$ for $12 \mathrm{~h}$ to remove residual water,

ii) SBA-15 was added in $50 \mathrm{~mL}$ of solvent (toluene or ethanol) with vigorous stirring,

iii) In both cases (toluene or ethanol), $3.03 \mathrm{~g}$ of APTES (i.e. $13.7 \mathrm{mmol}$ of APTES) was added to solution,

iv) In each case, functionalization was studied at $298 \mathrm{~K}$ under nitrogen or air atmosphere.

v) Finally, sample was washed with ethanol and dried at $373 \mathrm{~K}$ for $24 \mathrm{~h}$.

Samples labeling: C623 corresponds to pristine material (SBA15 calcined at $623 \mathrm{~K}$ ). For functionalized samples, the first letter corresponds to solvent used: " $E$ " stands for ethanol and " $T$ " stands for toluene. Next, functionalization temperature was indicating by a number (298 K). Finally, a letter "N", signals that functionalization was conducted under nitrogen atmosphere, and the absence of this letter implies an air atmosphere. For example, E298N is a sample functionalized at $298 \mathrm{~K}$ using ethanol and under a nitrogen atmosphere (viz Fig. 1).

\subsection{Characterization techniques}

Samples textural properties were determined by $\mathrm{N}_{2}$ adsorption, SEM, and TEM.

- Nitrogen sorption isotherms were performed on a Micromeritics ASAP 2020 system at liquid nitrogen temperature $(77 \mathrm{~K})$. Before adsorption measurements, SBA-15 sample was degassed at $373 \mathrm{~K}$ during $12 \mathrm{~h}$. The specific surface area of porous solid samples was calculated by multiple-point Brunauer-Emmett-Teller (BET) method in the relative pressure range $\mathrm{p} / \mathrm{p}^{0}=0.05-0.25$

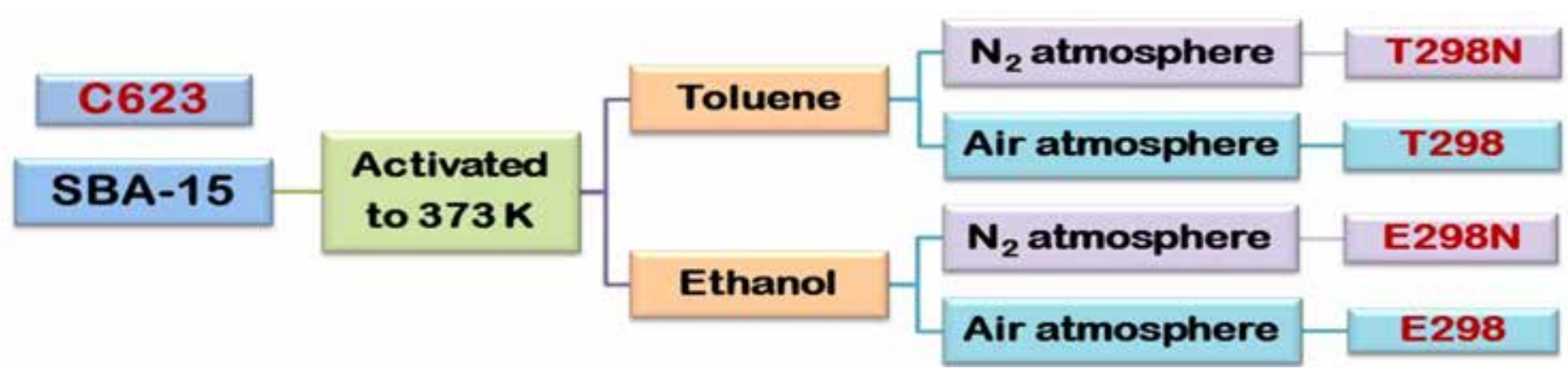

Fig. 1. SBA-15 sample is divided in four portions; each portion is being activated at $373 \mathrm{~K}$. Two portions are functionalized using toluene as solvent, and the other two using ethanol as solvent. For each solvent, one portion was functionalized under nitrogen atmosphere and the other portion was functionalized under air atmosphere. 
[25]. Pore size distribution curves were computed by using non-local density functional theory (NLDFT) [26]. Pore volumes were determined at $\mathrm{p} / \mathrm{p}^{0}$ value of 0.95 (using Gurvich rule) [27].

- Transmission Electron Microscopy (TEM) technique was used to determine the internal structure of SBA-15 materials, showing hexagonal structure and mean pore size. The analysis was performed on a high-resolution Transmission Electron Microscopy, HRTEM Jeol 2100F, using a field emitter as light source and accelerating voltage of $200 \mathrm{kV}$.

- Scanning Electron Microscopy (SEM) was used to determine the morphology of porous materials. This analysis was performed on a LEO 1450 VP electron microscope, operated at an acceleration voltage of $15 \mathrm{kV}$.

Silanol species was examined by ${ }^{29} \mathrm{Si}$ nuclear magnetic resonance (NMR) in a Bruker Advace II300 spectrometer operating at $59.62 \mathrm{MHz}$ for ${ }^{29} \mathrm{Si}$. The ${ }^{29} \mathrm{Si}$ NMR spectra were referenced to tetramethylsilane. Moreover, ${ }^{13} \mathrm{C}$ NMR spectra were carried out to show the presence of carbons from aminopropyl groups.

Finally, in order to evaluate the $\mathrm{CO}_{2}$ adsorption capacity of functionalized materials, $\mathrm{CO}_{2}$ adsorption isotherms at 283 $\mathrm{K}$ were obtained on Quantachrome Autosorb-1 equipment in the pressure interval from 0.001 to 1.000 bar. Samples were outgassed at $373 \mathrm{~K}$ for $12 \mathrm{~h}$ under vacuum before the measurements.

\section{Results and discussion}

\section{$3.1 \mathrm{~N}_{2}$ adsorption results}

Fig. 2 presents $\mathrm{N}_{2}$ adsorption isotherms for samples C623, E268, E298N, T298 and T298N, corresponding to pristine material and functionalized materials, respectively. It can be note that all adsorption isotherms are type IV(a) and H1 hysteresis loop, characteristic of materials exhibiting a narrow range of uniform mesopore size [27]. One can observe in Fig. 2 that hysteresis cycle of functionalized materials shows a leftward shift, it is exhibited by dotted lines. This behavior is caused by a decrease of mesopores size. It is worth noting that isotherm curvature at low pressure, decreases when the materials are functionalized, because microporosity is blocked by APTES molecules [28]; as it is known that adsorption at low pressure is mainly due to adsorption in micropores [29-31]. The main consequences of functionalization are two: i) micropore blocking and ii) a decrease of mesopore size. It produces a diminution of pore volume. Materials E298, E298N, T298, and T298N showed a decrease in their pore volume with regard to pristine material (C623) of 38, 47, 45, and 58\%, respectively, of Table 1, data was calculated from nitrogen adsorption isotherm. It is expected that better functionalization of the material cause greater changes in the textural properties with respect to the pristine material.

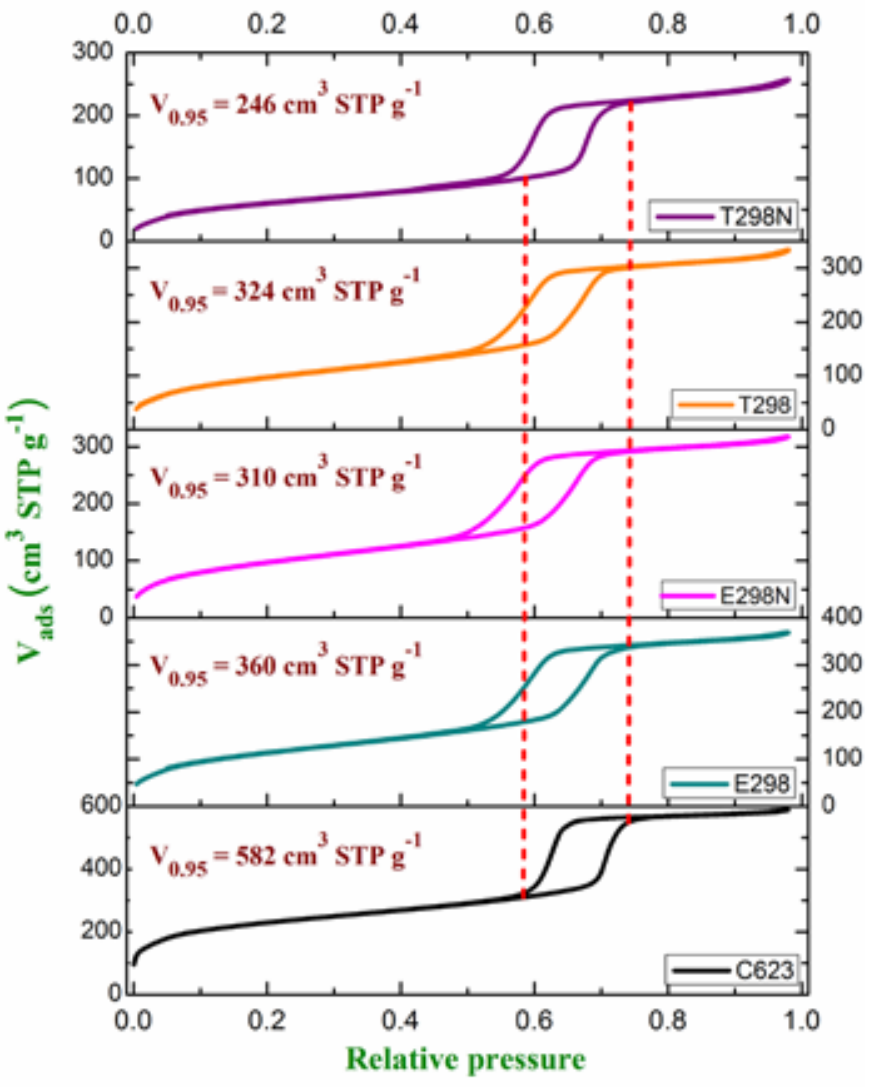

Fig. 2. $\mathrm{N}_{2}$ isotherms of pristine SBA-15 and amino functionalized materials at $298 \mathrm{~K}$.

Fig. 3 presents pore size distribution function (PSD), calculated by non-local density functional theory method, from desorption curve of nitrogen isotherms. It should be noted that the presence of micropores in material C623 (pores $<2.0 \mathrm{~nm}$ ) tend to disappear in functionalized samples. In the mesopore region, from 5.0 to $9.0 \mathrm{~nm}$, a pore size reduction occurs for functionalized samples with respect to pristine sample (note a left-shift in pore size distribution), indicating that APTES molecules have been successfully anchored in mesopores. It produces a pore size distribution between 5 and $7 \mathrm{~nm}$, this pore population continues accessible to $\mathrm{N}_{2}$ molecules (molecular diameter 0.364 $\mathrm{nm}$ ). On the other hand, for pore size from 2.0 to $5.0 \mathrm{~nm}$, nitrogen adsorbed volume disappears, indicating blockade of these nanopores.

The systems E298 and T298 present very similar pore size distribution, indicating that to functionalize under air atmosphere, the solvent does not have a significant role over the PSD. Conversely, when comparing PSD from systems E298N and T298N, both functionalized under nitrogen atmosphere, the next differences are observed: i) toluene causes a full obstruction of micropores and mesoporous from 2.0 to $5.0 \mathrm{~nm}$, and ii) toluene origins a narrower PSD than ethanol (viz Fig. 3), the width of PSD function is distributed on an interval of $2.22 \mathrm{~nm}$ for E298N, and $1.65 \mathrm{~nm}$ for T298N; these quantities were calculated at a constant value on the $\mathrm{Y}$ axis $=0.004 \mathrm{~cm}^{3} \AA^{-1} \mathrm{~g}^{-1}$. 


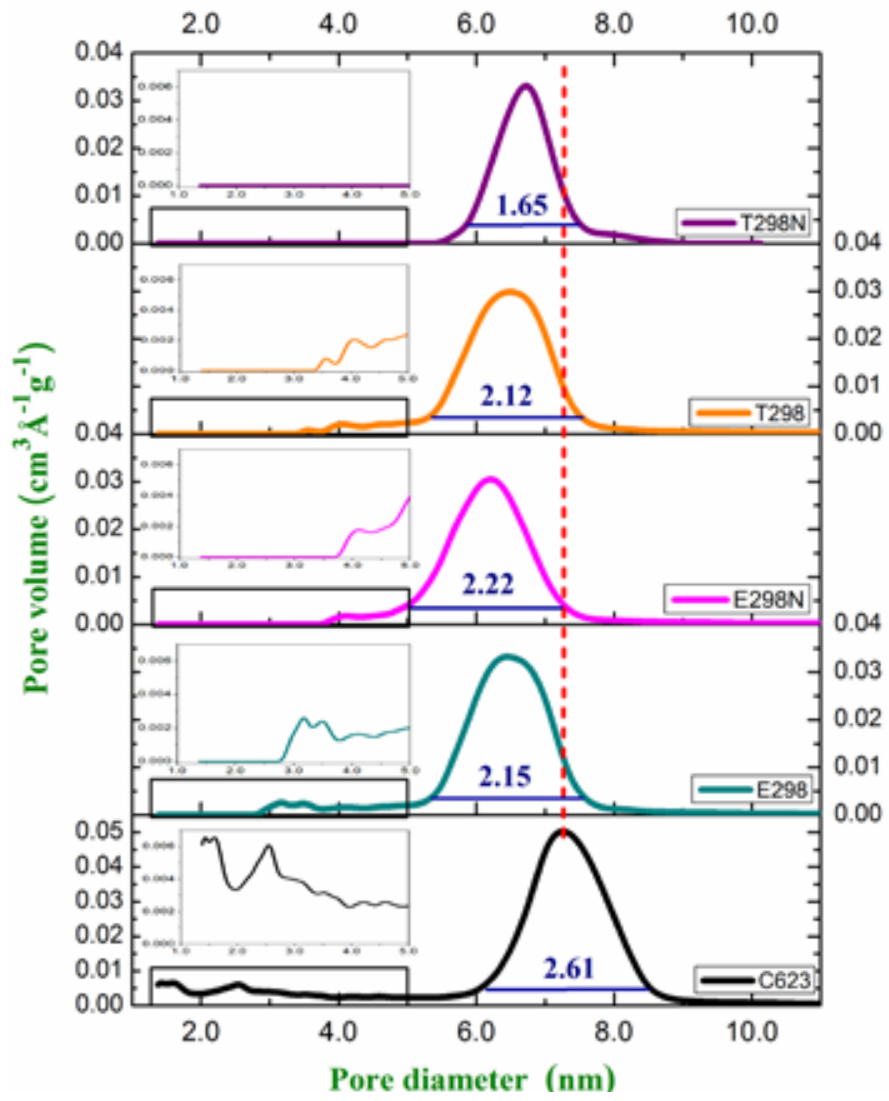

Fig. 3. NLDFT of pristine SBA-15 and amine functionalized materials at $298 \mathrm{~K}$ using ethanol or toluene as functionalization solvent.

Grafting effects on textural properties of mesoporous silica samples is summarized in Table 1. Pore size, specific surface area, and pore volume are found to decrease after modification. All functionalized materials do not present micropore volume. Functionalized samples E298 and T298 present a similar total pore volume of 0.56 and $0.52 \mathrm{~cm}^{3} \mathrm{~g}^{-1}$, respectively, meanwhile E298N and T298N presented lower values, i.e. 0.49 and $0.40 \mathrm{~cm}^{3} \mathrm{~g}^{-1}$, correspondingly. By contrasting samples C623 and T298N, the following functionalization effects are observed: i) specific surface area diminishes from 793 to $223 \mathrm{~m}^{2} \mathrm{~g}^{-1}$, and ii) average pore size is reduced from 7.3 to 6.7 $\mathrm{nm}$. In general, because of material functionalization, mean pore size reductions were found to be between 0.6 and $1.1 \mathrm{~nm}$; this can be due to the anchoring of APTES (inside mesopores [32]). Indeed, $0.5 \mathrm{~nm}$ is the size of APTES molecule free and without interactions, but inside porous solid, interactions APTES-surface and APTES-APTES produce a diminution of APTES size. Therefore, observed pore size changes can be due to APTES molecules anchored at surface and having sizes smaller than $0.5 \mathrm{~nm}$.

The behavior in textural changes could be explained as follows described:

i) Effect of water present. Water could be provided by atmosphere humidity as in the case of functionalization under air condition. An increment in the concentration of water accelerates the alkoxide hydrolysis reaction. This acceleration could produce insoluble species by early condensation of APTES molecules. APTES condensation reduces significantly the amount of APTES in solution available for functionalization. Then, functionalization performed under nitrogen atmosphere presented more textural changes than functionalization under air atmosphere.

ii) Polarity of solvents. APTES is more soluble in ethanol than in toluene [24]. Therefore, in ethanol condensation reaction between APTES molecules becomes very relevant, decreasing considerably APTES concentration (similar effect to water), affecting the performance of surface functionalization. Whereas in toluene, APTES condensation reaction is not significant, allowing a greater availability of APTES molecules to react with the surface, resulting in a more efficient functionalization. This make possible to form APTES multilayers on the surface which causes increased pore blockage.

\section{2 ${ }^{29} \mathrm{Si} \mathrm{RMN}$ and ${ }^{13} \mathrm{C}$ results}

As it was aforementioned, pristine SBA-15 has a definite amount of silanol groups, these groups are responsible of the interaction between SBA-15 and APTES molecule. In NMR, silanol groups ( $\mathrm{Si}-\mathrm{OH}$ bonds) and siloxanes ( $\mathrm{Si}-\mathrm{O}-\mathrm{Si}$ bonds) are labeled as "Q". The R-Si bonds (where R represents an organic residue) present in APTES molecules, signals provided by this bonds are assigned as "T" sites, as shown in Fig. 4.

Table 1: Textural properties of pristine SBA-15 and functionalized materials.

\begin{tabular}{cccccc}
\hline $\begin{array}{c}\text { Sample } \\
\text { label }\end{array}$ & $\begin{array}{c}\mathrm{a}_{\mathrm{s}}(\mathrm{BET}) \\
\left(\mathrm{m}^{2} \mathrm{~g}^{-1}\right)\end{array}$ & $\begin{array}{c}\mathrm{V}_{\text {MICRO }} \\
\left(\mathrm{cm}^{3} \mathrm{~g}^{-1}\right)\end{array}$ & $\begin{array}{c}\mathrm{V}_{\text {MESO }} \\
\left(\mathrm{cm}^{3} \mathrm{~g}^{-1}\right)\end{array}$ & $\begin{array}{c}\mathrm{V}_{\mathrm{p}} \\
\left(\mathrm{cm}^{3} \mathrm{~g}^{-1}\right)\end{array}$ & $\begin{array}{c}\mathrm{D}_{\mathrm{p}(\mathrm{NLDFT})} \\
(\mathrm{nm})\end{array}$ \\
\hline $\mathbf{C 6 2 3}$ & 793 & 0.13 & 0.86 & 0.99 & 7.3 \\
$\mathbf{E 2 9 8}$ & 412 & 0.00 & 0.56 & 0.56 & 6.5 \\
E298N & 356 & 0.00 & 0.49 & 0.49 & 6.2 \\
T298 & 354 & 0.00 & 0.52 & 0.52 & 6.5 \\
T298N & 223 & 0.00 & 0.40 & 0.40 & 6.7 \\
\hline
\end{tabular}

$\mathrm{a}_{\mathrm{s}}(\mathrm{BET}) \equiv \mathrm{BET}$ specific area; $\mathrm{V}_{\text {MICRO }} \equiv$ micropore volume $; \mathrm{V}_{\text {MESO }} \equiv$ mesopore volume; $\mathrm{V}_{\mathrm{p}} \equiv$ pore volume $\left(\mathrm{p} / \mathrm{p}^{0}=0.95\right) ; \mathrm{D}_{\mathrm{p}(\mathrm{NLFDT})} \equiv$ pore diameter. 


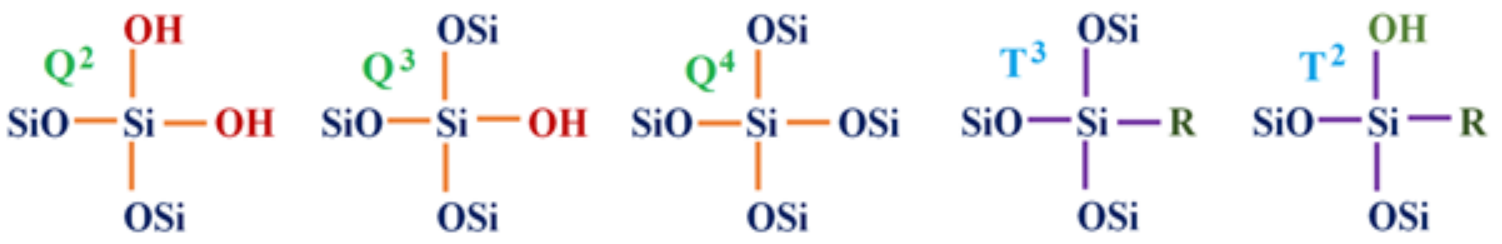

Fig. 4. $Q^{2}$ : geminal silanols; $Q^{3}$ : free and vicinal silanols; $Q^{4}$ : siloxane groups; $T^{2}: \operatorname{SiR}(O S i)_{2}(O H)$ groups; and $T^{3}: S i R(O S i){ }_{3}$ groups. The $T^{2}$ and $\mathrm{T}^{3}$ peaks are due to the Si atoms of different environments in the organosilane APTES [33].

Analysis of ${ }^{29} \mathrm{Si}$ was carried out to evaluate the evolution of the "Q" bands in functionalized materials, respect to the pristine material (C623). $\mathrm{Q}^{2}, \mathrm{Q}^{3}$ and $\mathrm{Q}^{4}$ sites, are assigned at chemical displacements $\delta=-93,-103$ and $-112 \mathrm{ppm}$, respectively. The four functionalized samples present signals corresponding to $\mathrm{T}^{2}$ and $\mathrm{T}^{3}$ bands, assigned at $\delta=-60$ y $-68 \mathrm{ppm}$, respectively [33-36].

Fig. 5 shows ${ }^{29} \mathrm{Si}$ NMR spectra HPDEC at region corresponding to "Q" bands (-90 to $-125 \mathrm{ppm}$ ). It can be observe that all functionalized samples show a decrease in both, $\mathrm{Q}^{2}$ and $\mathrm{Q}^{3}$ signals, which are associated with loss of silanol groups. This could be explained by the fact that under synthesis condition, the most likely way to diminish silanol groups is condensation of APTES molecules on SBA-15 surface $[19,37]$.The latter means that the decreasing of $\mathrm{Q}^{2}$ and $\mathrm{Q}^{3}$ areas ratio (with respect to total area) is related with APTES molecules chemically linked on the surface. The functionalized samples shows $\mathrm{T}$ bands signals, indicating presence of APTES molecules. Fig. 6 illustrates different APTES molecules interaction, i.e. an APTES molecule can react with surfaces or with another APTES molecule. Therefore, the relation between T signal and APTES molecules linked to surfaces is not a direct relation.

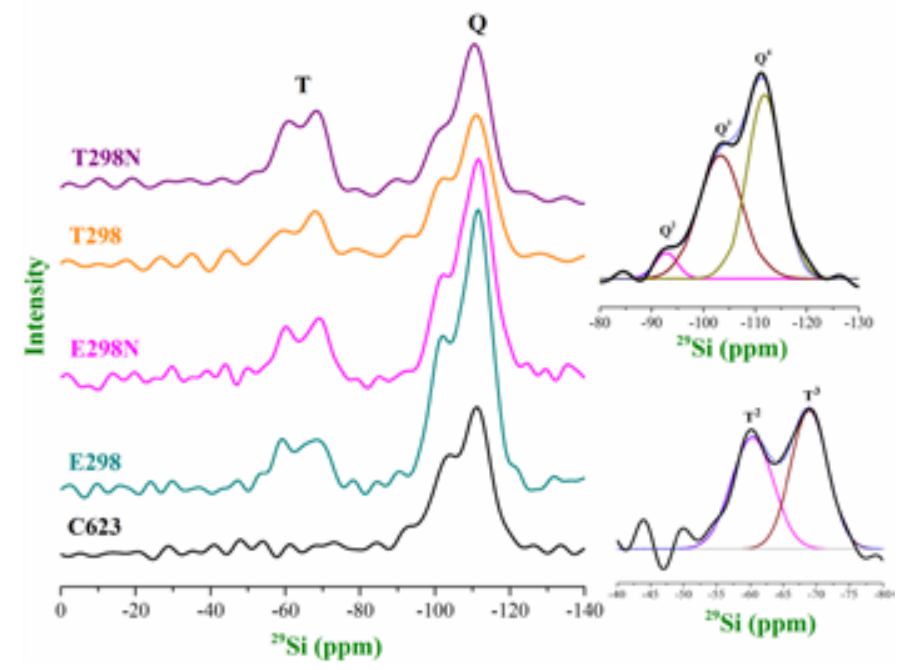

Fig. 5. ${ }^{29} \mathrm{Si}$ HPDEC spectrum of pure and functionalized SBA-15.

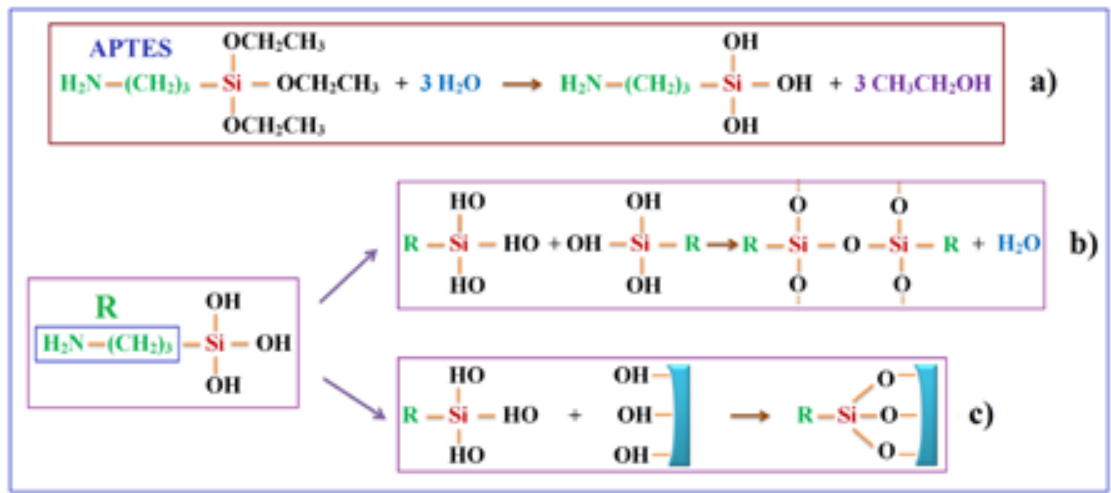

Fig. 6. a) APTES molecules hydrolysis. Chemical interaction routes of APTES molecules: b) between APTES molecules and c) APTES molecules with silanol groups on material surface. 
Results coming from deconvolutions of ${ }^{29} \mathrm{Si}$ NMR spectra are presented in Table 2. There are two parts in Table 2, the first one corresponds to $\mathrm{Q}$ bands analysis, i.e. considering only areas corresponding to $\mathrm{Q}^{2}, \mathrm{Q}^{3}$ and $\mathrm{Q}^{4}$ bands. Region where the silanol groups are observed. It can be observe that ratio $\left(\mathrm{Q}^{2}+\right.$ $\left.\mathrm{Q}^{3}\right) /\left(\mathrm{Q}^{2}+\mathrm{Q}^{3}+\mathrm{Q}^{4}\right)$ decreases for functionalized samples, with regard to pristine sample. This result indicates that condensation between APTES molecules and silanol groups was carried out. For instance, samples T298 and T298N present the highest decrement of silanol species, 0.17 and 0.21 , respectively.

The second part of Table 2 considers areas of both, Q and $\mathrm{T}$ bands. Functionalized materials using toluene present higher $\mathrm{T}$ bands ratio value than functionalized materials in ethanol. In general, the area ratio $\left(\mathrm{T}^{2}+\mathrm{T}^{3}\right) /\left(\mathrm{Q}^{2}+\mathrm{Q}^{3}+\mathrm{Q}^{4}+\mathrm{T}^{2}+\mathrm{T}^{3}\right)$ increases as decreasing of the area ratio $\left(\mathrm{Q}^{2}+\mathrm{Q}^{3}\right) /\left(\mathrm{Q}^{2}+\mathrm{Q}^{3}+\mathrm{Q}^{4}\right)$, behavior that is not proportional. For example, T298N sample presents the highest ratio of $\mathrm{T}$ groups, 0.38 and also exhibits the largest ratio reduction of silanol species, 0.21 . These results indicate that there is condensation between APTES molecules.

Fig. 7 shows the ${ }^{13} \mathrm{C}$ NMR spectrum of T298N sample. It is pertinent to mention that the behaviors of other functionalized samples are similar. It can be note the presence of three carbon signals, coming from carbon atoms under different chemical environments in APTES molecule. These signals are assigned in Fig. 7, indicating that APTES amino-propyl group is not affected by synthesis process.

Table 2: Area ratio obtained from spectra ${ }^{29} \mathrm{Si}$ HPDEC corresponding to Q and $\mathrm{T}$ bands.

\begin{tabular}{ccccccc} 
& $\begin{array}{c}\text { Sample } \\
\text { name }\end{array}$ & $\mathbf{C 6 2 3}$ & $\mathbf{E 2 9 8}$ & $\mathbf{E 2 9 8 N}$ & $\mathbf{T 2 9 8}$ & $\mathbf{T 2 9 8 N}$ \\
\hline BANDS & $\mathbf{Q}^{\mathbf{2}}$ & 0.05 & 0.02 & 0.00 & 0.08 & 0.04 \\
$\mathbf{Q}$ & $\mathbf{Q}^{3}$ & 0.43 & 0.39 & 0.36 & 0.22 & 0.23 \\
& $\mathbf{Q}^{4}$ & 0.52 & 0.59 & 0.64 & 0.70 & 0.73 \\
& $\mathbf{Q}^{2}+\mathbf{Q}^{3}$ & 0.48 & 0.41 & 0.36 & 0.30 & 0.27 \\
& & & & & & \\
& $\mathbf{Q}^{2}$ & 0.05 & 0.02 & 0.0 & 0.06 & 0.00 \\
$\mathbf{B A N D S}$ & $\mathbf{Q}^{3}$ & 0.43 & 0.26 & 0.17 & 0.19 & 0.15 \\
$\mathbf{Q}+\mathbf{T}$ & $\mathbf{Q}^{4}$ & 0.52 & 0.56 & 0.62 & 0.54 & 0.47 \\
& $\mathbf{T}^{2}$ & 0.00 & 0.08 & 0.10 & 0.08 & 0.23 \\
& $\mathbf{T}^{3}$ & 0.00 & 0.08 & 0.11 & 0.13 & 0.15 \\
& $\mathbf{T}^{2}+\mathbf{T}^{3}$ & 0.00 & 0.16 & 0.21 & 0.21 & 0.38 \\
\hline
\end{tabular}

$\mathrm{Q}^{2} \equiv$ geminal silanols; $\mathrm{Q}^{3} \equiv$ free and vicinal silanols; $\mathrm{Q}^{4} \equiv$ siloxane groups.

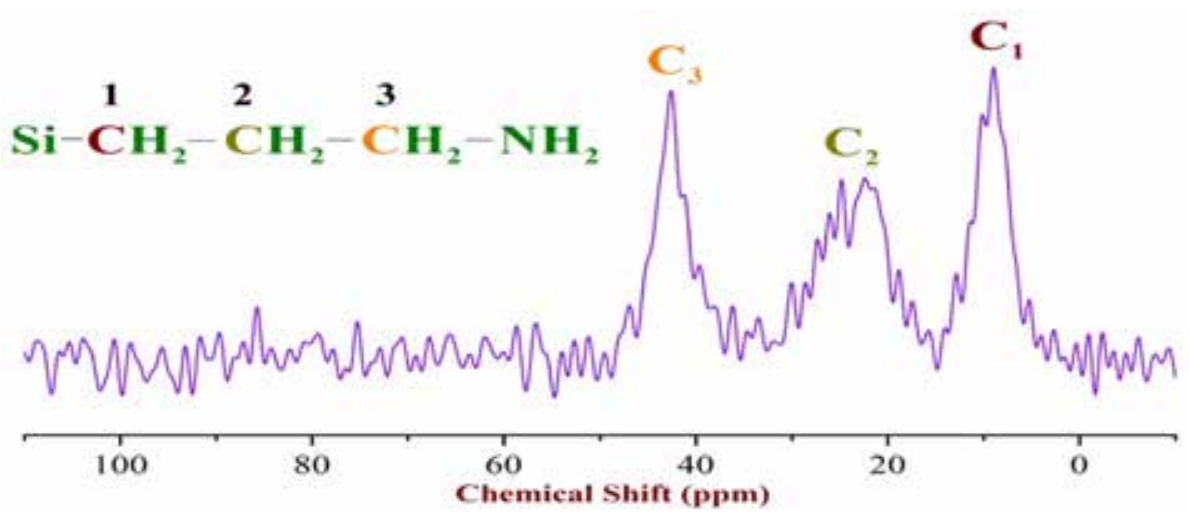

Fig. 7. ${ }^{13} \mathrm{C}$ NMR of $\mathrm{T} 298 \mathrm{~N}$ material. 


\subsection{TEM and SEM results}

Fig. 8 shows TEM (8a and $8 \mathrm{~b})$ and SEM (8c and $8 \mathrm{~d})$ images of C623 and T298N samples. SEM images of both samples have a fibrillar shape with an average length longer than $10 \mu \mathrm{m}$, this is visible in Fig. 8a and 8b. The study of sample T298N shows no significant changes on shape of fibrillar entities with respect to its predecessor system C623 (Fig. 8b). With regard to TEM analysis, both samples show a hexagonal structure of cylindrical pores, indicating that hexagonal arrangement of the pores is invariable despite of functionalization (viz Fig. 8c and 8d). An approximate measurement of the pore diameter is shown in TEM micrographs, indicating a decrease in size from $6.0 \mathrm{~nm}$ to $4.0 \mathrm{~nm}$. This indicates that APTES molecules form a coating on SBA-15 pore surface.
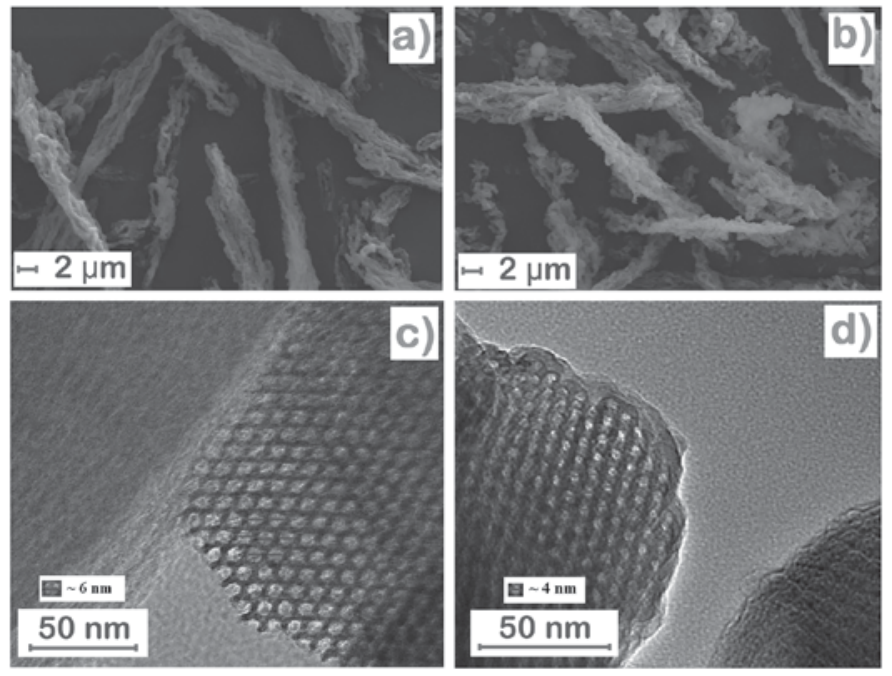

Fig. 8. Micrographs SEM and TEM of material C623 and T298N a) C623 (SEM), b) T298N (SEM), c) C623 (TEM), and d) T298N (TEM).

\section{4 $\mathrm{CO}_{2}$ adsorption results}

The efficiency of Amino-functionalization is obtained considering $\mathrm{CO}_{2}$ adsorption at low pressure (relative pressure $<0.1$ ) as chemisorption. A molecule of $\mathrm{CO}_{2}$ react with two amine groups. Fig. 9 shows a pathway for carrying out the process [38-41].

Fig. 10a shows $\mathrm{CO}_{2}$ adsorption isotherms for pristine and functionalized samples. It is important to note that the pristine SBA-15 (C623) material has no affinity for $\mathrm{CO}_{2}$, which is demonstrated with the adsorption isotherm, where at any pressure the predominant phenomenon observed is physisorption, presenting a linear behavior as function of pressure, i.e., obeying Henry's law.

The isotherms of functionalized samples present two behaviors: i) at low pressures $\mathrm{CO}_{2}$ molecules are chemisorbed by the amino groups, producing a pronounced adsorption; and, ii) then the amino groups are saturated, $\mathrm{CO}_{2}$ molecules are physisorbed on the silica surface, and therefore $\mathrm{CO}_{2}$ adsorption is less intense than at low pressures $[42,43]$.

Sample functionalized under air atmosphere, $c f$ Fig. 10a, T298 adsorbs more at low pressures with respect to C623 and E298; indicating a greater presence of amino groups. However, at higher pressures of $0.4 \mathrm{bar}$, where only physisorption takes place, the adsorption capacity of T298 decreases. On the other hand, E298 adsorbs little at low pressure, indicating a low presence of amine groups, and its adsorption capacity increases when pressure increases, this as a result of physisorption on a high superficial area. This causes a cross between both isotherms at a pressure of 0.43 bar where E298 exceeds the $\mathrm{CO}_{2}$ adsorption capacity of T298, which causes that at 1.0 bar of pressure the amount adsorbed is greater for E298.

Now, focusing attention on materials that were functionalized under nitrogen atmosphere, both materials, E298N and $\mathrm{T} 298 \mathrm{~N}$, at 1.0 bar adsorb the same amount of $\mathrm{CO}_{2}(1.43 \mathrm{mmol}$

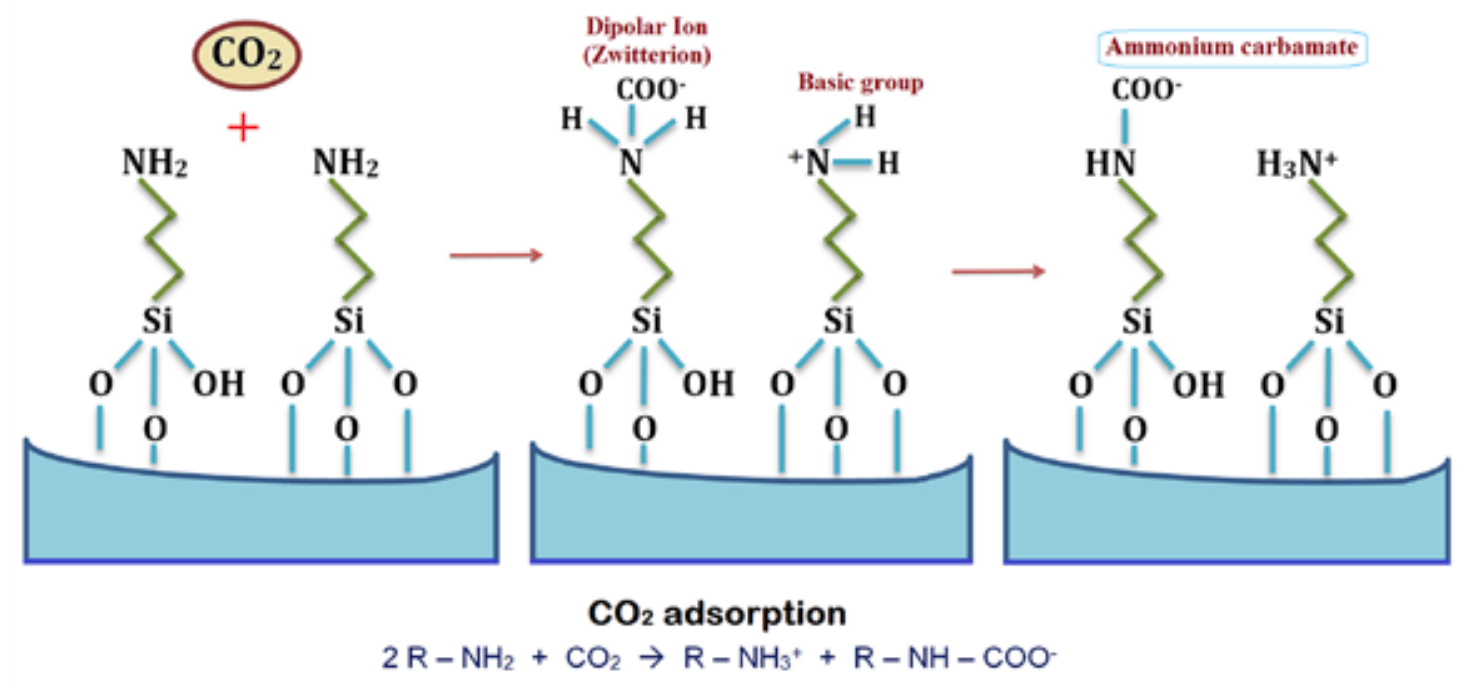

Regeneration

$$
\mathrm{R}-\mathrm{NH}-\mathrm{COO}+\mathrm{R}-\mathrm{NH}_{3}{ }^{+}+\mathrm{Heat} \rightarrow \mathrm{CO}_{2}+2 \mathrm{R}-\mathrm{NH}_{2}
$$

Fig. 9. An example of $\mathrm{CO}_{2}$ chemisorption mechanism on amino-groups on SBA-15. 

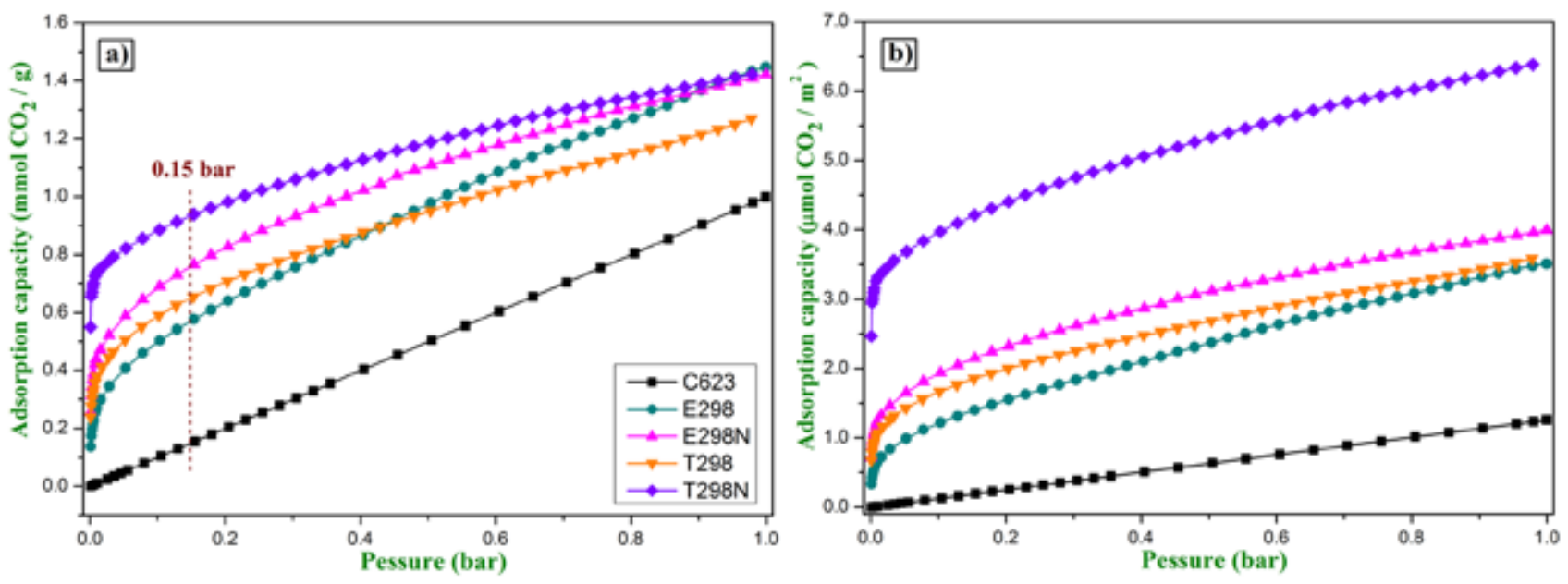

Fig. 10. $\mathrm{CO}_{2}$ adsorption of pristine and amino-functionalized SBA-15. a) $\mathrm{mmol} \mathrm{CO}_{2} / \mathrm{g}$ and b) $\mu \mathrm{mol} \mathrm{CO}_{2} / \mathrm{m}^{2}$.

$\mathrm{CO}_{2} / \mathrm{g}$ ), however, at 0.15 bar, the typical composition of a gaseous industrial effluent is $15 \%$ in volume of $\mathrm{CO}_{2}$, if an ideal behavior is considered, the partial pressure of $\mathrm{CO}_{2}$ would be 0.15 bar [44], T298N adsorbs $20 \%$ more than E298N ( 0.940 against $0.766 \mathrm{mmol} \mathrm{CO}_{2} / \mathrm{g}$ ) and $83 \%$ more than pristine material $\left(\mathrm{C} 623,0.153 \mathrm{mmol} \mathrm{CO}_{2} / \mathrm{g}\right)$.

The functional materials exhibit different textural properties that affect the performance of $\mathrm{CO}_{2}$ adsorption. In order to comparison, without significant textural effects, the $\mathrm{CO}_{2}$ adsorption isotherms are normalized using their surfaces areas ( $\mu$ mol of $\mathrm{CO}_{2} / \mathrm{m}^{2}$ ), shown in Fig. 10b. In this perspective no crossing of the isotherms is observed. Based on the amount adsorbed per square meter, materials present the following performance T298N> E298N> T298> E298. Functional materials in the nitrogen atmosphere adsorb a greater amount of $\mathrm{CO}_{2}$ per square meter and toluene as a solvent present the better performance in both atmospheres. T298N present the greater capacity of $\mathrm{CO}_{2}$ adsorption per square meter in spite of having the greater reduction of area with respect to the material pristine. This corroborate that a better functionalization causes greater textural changes in the materials.

\section{Conclusion}

The main conclusion of this work is that APTES anchorage on SBA-15 surface is favored by the use of both, low polar solvents and minimize water presence in the atmosphere, i.e., toluene as solvent and a nitrogen atmosphere during the functionalization process. Material textural changes are a function of the quantity of APTES molecules anchored. The diminution of silanol groups is a consequence of APTES molecules anchorage.

\section{Acknowledgements}

We thank to the Consejo Nacional de Ciencia y Tecnología (CONACyT) for the support granted for the development of this work. To the network SEP-PROMEP "Diseño Nanoscópico y Textural de Materiales Avanzados", with the Project "Síntesis y Fisicoquímica de Materiales Mesoporosos" (UAM-I CA-31 Fisicoquímica de Superficies). Our thanks to Marco Antonio Vera and Atilano Gutierrez by NMR analysis, and Patricia Castillo by analysis TEM of the Universidad Autónoma Metropolitana-Iztapalapa. Also René Guardián by analysis SEM of Centro de Investigación en Ingeniería y Ciencias Aplicadas (CIICAp), Universidad Autónoma del Estado de Morelos.

\section{References}

1. Zhao, D.; Huo, Q.; Feng, J.; Chmelka, B. F.; Stucky, G. D. J. Am. Chem. Soc. 1998, 120 (24), 6024-6036.

2. Zhao, D.; Sun, J.; Li, Q.; Stucky, G. D.; Barbara, S. Chem. Mater 2000, 12, 275-279.

3. Zhao, D.; Feng, J.; Huo, Q.; Melosh, N.; Fredrickson, G. H.; Chmelka, B. F.; Stucky, G. D. Science 1998, 279 (5350), 548-552.

4. Liu, Y.; Lee, J. Y.; Hong, L. Journal of Power Sources 2002, 109, 507-514.

5. Wang, X. L.; Mei, A.; Li, M.; Lin, Y.; Nan, C. W. Solid State Ionics 2006, 177 (15-16), 1287-1291.

6. Sanz, R.; Calleja, G.; Arencibia, A.; Sanz-Perez, E. S. J. Mater. Chem. A 2013, 1 (6), 1956-1962.

7. Calleja, G.; Sanz, R.; Arencibia, A.; Sanz-Pérez, E. S. Top. Catal. 2011, 54, 135-145.

8. Wei, Y.; Li, X.; Zhang, R.; Liu, Y.; Wang, W.; Ling, Y.; Mohamed, A.; Zhao, D. Nat. Publ. Gr. 2016, No. January, 1-11.

9. Wang, L.; Ma, L.; Wang, A.; Liu, Q.; Zhang, T. Chinese J. Catal. 2007, 28 (9), 805-810.

10. Liu, X.; Zhou, L.; Fu, X.; Sun, Y.; Su, W.; Zhou, Y. Chemical Engineering Science 2007, 62, 1101-1110.

11. Kim, S. N.; Son, W. J.; Choi, J. S.; Ahn, W. S. Microporous Mesoporous Mater 2008, 115 (3), 497-503.

12. Hiyoshi, N.; Yogo, K.; Yashima, T. Microporous Mesoporous Mater 2005, 84 (1-3), 357-365. 
13. Ryoo, R.; Ko, C. H.; Kruk, M.; Antochshuk, V.; Jaroniec, M. J. Phys. Chem. B 2000, 104 (48), 11465-11471.

14. Thielemann, J.; Girgsdies, F.; Schlögl, R.; Hess, C. Beilstein J. Nanotechnol. 2011, 2 (1), 110-118.

15. Ojeda-López, R.; Pérez-Hermosillo, I. J.; Esparza-Schulz, J. M.; Cervantes-Uribe, A.; Domínguez-Ortiz, A. Adsorption 2015, 21 (8), 659-669.

16. Ojeda-López, R.; Pérez-Hermosillo, I. J.; Esparza-Schulz, J. M.; Domínguez-Ortiz, A. Av. en Química 2014, 9 (1), 21-28.

17. Soler-Illia, G. J. a a; Azzaroni, O. Chem. Soc. Rev. 2011, 40 (2), 1107-1150.

18. Melero, J. a.; Stucky, G. D.; van Grieken, R.; Morales, G. Journal of Materials Chemistry 2002, pp 1664-1670.

19. Chong, A. S. M.; Zhao, X. S. J. Phys. Chem. B 2003, 107 (46), 12650-12657.

20. Sanz, R.; Calleja, G.; Arencibia, A.; Sanz-Pérez, E. S. Microporous Mesoporous Mater 2012, 158, 309-317.

21. Lombardo, M. V; Videla, M.; Calvo, A.; Requejo, F. G.; Soler-illia, G. J. A. A. J. Hazard. Mater. 2012, 223-224, 53-62.

22. Szegedi, A.; Popova, M.; Goshev, I.; Mihály, J. J. Solid State Chem. 2011, 184 (5), 1201-1207.

23. Moritz, M.; Łaniecki, M. Appl. Surf. Sci. 2012, 258 (19), 7523-7529.

24. Lombardo, M. V. Universidad Nacional de San Martín. Instituto de Investigación e Ingeniería Ambiental. España. 2013.

25. Brunauer, S.; Emmett, P. H.; Teller, E. J. Am. Chem. Soc. 1938, 60 (1), 309-319.

26. Ravikovitch, P. I.; Neimark, A. V. J. Phys. Chem. B 2001, 105 (29), 6817-6823.

27. Thommes, M.; Kaneko, K.; Neimark, A. V.; Olivier, J. P.; Rodriguez-Reinoso, F.; Rouquerol, J.; Sing, K. S. W. Pure Appl. Chem. 2015, 87 (9-10), 1051-1069.

28. Pollock, R. A.; Walsh, B. R.; Fry, J.; Ghampson, I. T.; Melnichenko, Y. B.; Kaiser, H.; Pynn, R.; Desisto, W. J.; Wheeler, M. C.; Frederick, B. G. Chem. Mater 2011, 23 (17), 3828-3840.

29. Imperor-Clerc, M.; Davidson, P.; Davidson, A. J. Am. Chem. Soc. 2000, 122 (48), 11925-11933.
30. Galarneau, A.; Cambon, H.; Di Renzo, F.; Fajula, F. Langmuir 2001, 17 (26), 8328-8335.

31. Galarneau, A.; Cambon, H.; Di Renzo, F.; Ryoo, R.; Choi, M.; Fajula, F. New J. Chem. 2002, 27 (1), 73-79.

32. Savino, R.; Casadonte, F.; Terracciano, R. Molecules 2011, 16 (7), 5938-5962.

33. Ide, M.; El-Roz, M.; Canck, E. De; Vicente, A.; Planckaert, T.; Bogaerts, T.; Driessche, I. Van; Lynen, F.; Speybroeck, V. Van; Thybault-Starzyk, F.; Voort, P. Van Der. Phys. Chem. Chem. Phys. 2012, 15 (2), 642-650.

34. Wang, X.; Lin, K. S. K.; Chan, J. C. C.; Cheng, S. J. Phys. Chem. B 2005, 109 (5), 1763-1769.

35. Rahman, I. A.; Jafarzadeh, M.; Sipaut, C. S. Ceram. Int. 2009, 35 (5), 1883-1888.

36. Colilla, M.; Izquierdo-Barba, I.; Sánchez-Salcedo, S.; Fierro, J. L. G.; Hueso, J. L.; Vallet-Regí, M. Chem. Mater 2010, 22 (23), 6459-6466.

37. Wang, X.; Lin, K. S. K.; Chan, J. C. C.; Cheng, S. J. Phys. Chem. B 2005, 109 (5), 1763-1769.

38. Sanz-Pérez, E. S.; Olivares-Marín, M.; Arencibia, A.; Sanz, R.; Calleja, G.; Maroto-Valer, M. M. Int. J. Greenh. Gas Control 2013, 17, 366-375.

39. Knowles, G. P.; Graham, J. V; Delaney, S. W.; Chaffee, A. L. Fuel Processing Technology 2005, 86, 1435-1448.

40. Ünveren, E. E.; Monkul, B. Ö.; Sarıŏlan, Ş.; Karademir, N.; Alper, E. Petroleum 2016, 1-14.

41. Vilarrasa-García, E.; Cecilia, J. A.; Santos, S. M. L.; Cavalcante, C. L.; Jiménez-Jiménez, J.; Azevedo, D. C. S.; Rodríguez-Castellón, E. Microporous Mesoporous Mater 2014, 187, 125-134.

42. Danon, A.; Stair, P. C.; Weitz, E. J. Phys. Chem. C 2011, 115 (23), 11540-11549.

43. Chang, A. C. C.; Chuang, S. S. C.; Gray, M.; Soong, Y. Energy \& Fuels 2003, 17, 468-473.

44. Yuan, M. H.; Wang, L.; Yang, R. T. Langmuir 2014, 30 (27), 8124-8130. 